Brit. F. vener. Dis. (1972) 48, 144

\title{
A note on Trichomonas vaginalis and seminal fluid
}

\author{
W. K. BERNFELD
}

Dewi Sant Hospital, Pontypridd, Glamorgan

In 1969 the reported incidence of trichomonal infestations diagnosed in the venereal diseases clinics of England showed a male:female ratio of $1: 12.5$ (see Chief Medical Officer's Report, 1970), but there is a presumption that more men are infected than are diagnosed by the usual methods.

Rodecurt (1937), in a series of 25 men, found Trichomonas vaginalis in the seminal fluids of all patients whose sexual partners were infested but in none of those whose partners were not. A further case was that of a specialist, 'well versed in the field of trichomoniasis'. His wife had been treated for the condition on and off for 3 years, and 16 weeks after 'infection', trichomonads were found repeatedly in the semen. They remained alive as long as the spermatozoa which frequently became entangled with them.

Kolesoff (1950) described phagocytosis of spermatoza by trichomonads from vaginal secretion seen both in wet and in Romanowsky-stained preparations.

Whittington (1951) examined the seminal fluids of 26 men whose wives had a trichomonal condition. She demonstrated the organism in seven, using cultures as well as fresh material.

Bertrand and Leulier (1960) examined the sexual partners of 27 women with trichomonal vaginitis; of the twenty men infested, fourteen had trichomonads in the seminal fluid.

Gaffuri and Poggio (1968) and Nicora and Giarola (1968) hinted that Trichomonas vaginalis might be a contributory factor to conjugal sterility; on the other hand Davidson (1970), who examined over 30,000 seminal fluids, was convinced that a substantial trichomonal infestation was compatible with a high fertility rate.

\section{Present study}

From time to time men are referred to the Pontypridd V.D. Clinic by general practitioners, gynaecologists, and even a solicitor, for the purpose of seminal assessment, and since 1951 over 600 fluids have been

Received for publication May 26, 1971

Address: 39 Gabalfa Rd., Cardiff examined (Bernfeld, 1964). When Walton (1969) reported that Papanicolau-stained slides of seminal fluid could reveal trichomonads as clearly as cervical cytology smears, this method of examination was adopted as an addition to the routine analysis. Two seminal smears were prepared from each patient, fixed with cytology fixative and sent to Dr. M. Davies of the Cytology Service, St. Woolo's Hospital, Newport, Mon. Here the two smears were examined after Papanicolau and Romanowsky staining.

The stained films from 85 men were examined, including those of four post-vasectomy cases. All men were asked to micturate before producing the masturbation specimen in the clinic, but seven had produced the specimen at home.

From the 85 specimens, seven definite positive results were obtained, and in an eighth case the parasite was reported as 'probably present'. The semen of this 'doubtful' positive case was produced at home, the others in hospital.

Four of the eight specimens positive for trichomonads showed counts of between $20 \mathrm{~m}$. and $200 \mathrm{~m}$. live spermatozoa per $\mathrm{ml}$., one $9 \mathrm{~m}$., one extreme oligozoospermia, one necrospermia, and one azoospermia. (In the last mentioned case, there was a history of an operation for undescended testicles at the age of 24 years.)

Of the 73 negative semens 41 (excluding the four post-vasectomy cases) showed counts of less than $20 \mathrm{~m}$. spermatozoa per ml., or azoospermia). All the eight patients with positive findings (and the majority of the others) had abstained from sexual intercourse for at least 8 days before the test.

It was not possible to examine the wives, but their general practitioners were informed.

\section{Summary}

The literature concerning Trichomonas vaginalis in the semen is reviewed. In the course of seminal analysis for infertility, Papanicolau-stained seminal smears from 85 men were examined for Trichomonas vaginalis, and eight positive cases were found. 
References

Bernfeld, W. K. (1964) Practitioner, 192, 780

Bertrand, P., and Leulier, J. (1960) 'First Canadian Symposium on Non-Gonococcal Urethritis and Human Trichomoniasis, Montreal'. Karger, Basel Chief Medical Officer (1970) 'Report for the Year 1969'. Brit. F. vener. Dis., 46, 502

Davidson, H. A. (1970) Personal communication

Gaffuri, S., and Poggio, A. (1968) Minerva ginec., 20, 1260

Kolesoff, A. P. (1950) Akush. Ginek., No. 6, 46

NicoRA, G., and Giarola, A. (1968) Ginec. prat., 19, 309

Rodecurt, M. (1937) Derm. Z., 74, 254
Walton, H. C. M. (1969) Brit. med. f., 2, 514

Whittington, M. J. (1951) f. Obstet. Gynaec. Brit. Cwlth, 58, 614

Une note sur Trichomonas vaginalis et liquide séminal

SOMMAIRE

La littérature concernant le Trichomonas vaginalis dans le sperme est passée en revue. A l'occasion d'études de sperme pour infertilité, des étalements du sperme de 85 hommes, colorés au Papanicolau, furent examinés pour recherche du Trichomonas vaginalis: il fut trouvé huit cas positifs. 